\title{
A identidade e a ideologia do Partido Republicano
}

\author{
Jheniffer Vieira de Almeida ${ }^{1}$ \\ Vitor de Moraes Peixoto ${ }^{2}$
}

\begin{abstract}
Resumo: Identidade partidária são as preferências por políticas públicas que distinguem um partido de outros. A ideologia situa o partido à esquerda, direita ou centro; conservadores ou progressistas, com ou sem intervenção estatal na economia. O Republicanos foi criado em 2005 e, desde então, tem aumentado gradualmente o número de parlamentares eleitos, sendo destaque em diversas eleiçóes de que participa. Esse trabalho tem como objetivo descrever a identidade e eixo ideológico do Republicanos. Para tal, usaremos como método a análise de conteúdo. O partido passou por três mudanças, deslocando-se à direita, tem atuado com políticas liberais no ponto de vista econômico e conservadorismo nos costumes.
\end{abstract}

Palavras Chave: Ideologia; programa de partido; Republicanos.

\section{The identity and ideology of the Republican Party}

\begin{abstract}
Party identities are the preferences for public policies that distinguish one party from others. Ideology places the party on the left, right or center; conservative or progressive, with or without state intervention in the economy. 'Republicanos' party was created in 2005 and since then, the number of elected parliamentarians has gradually increased and the party has being highlighted in several elections that it takes part in. This work aims to characterize the Republicans' identity and ideological axis. Therefore, we will use content analysis as a method. The party has gone through three changes, moving to the right. It has acted with liberal policies from the economic point of view and conservatism in customs.
\end{abstract}

Keywords: Ideology; party program;Republicans.

\footnotetext{
Doutoranda em Sociologia Política pela Universidade Estadual do Norte Fluminense Darcy Ribeiro; mestre em Sociologia Política pela Universidade Estadual do Norte Fluminense Darcy Ribeiro (2017); graduada em Ciências Sociais pela Universidade Federal Fluminense (2014). Participa do Grupo de Pesquisa Dinâmicas Territoriais, Cultura e Religião. Atuo estudando partidos políticos e religião sob metodologia qualitativa. E-mail: jheniffervi@gmail.com.

2 Doutor em Ciência Política (Ciência Política e Sociologia) pelo Instituto Universitário de Pesquisas do Rio de Janeiro (2010); mestre em Ciência Política (Ciência Política e Sociologia) pelo Instituto Universitário de Pesquisas do Rio de Janeiro (2004); graduado em Ciências Sociais pela Universidade Estadual do Norte Fluminense Darcy Ribeiro (2003). Atualmente é professor associado da Universidade Estadual do Norte Fluminense Darcy Ribeiro. Tem experiência na área de Ciência Política, com ênfase em Estudos Eleitorais e Partidos Políticos. E-mail: moraespeixoto@gmail.com
} 


\section{Introduçáo}

A criação do Republicanos se dá com a assinatura de eleitores interessados num novo modo de se fazer política. É essa a história de criação que o próprio partido eterniza. Para tal feito, foram colhidas mais de 450 mil assinaturas no ano de 2003. Em 2004, o partido foi registrado sob o nome de Partido Municipalista Renovador (PMR), e renovação era a promessa pretendida: "Na certeza de que a mudança no cenário político de nosso país é desejo de todos, o PMR foi criado para unir esforços, especialmente nesse sentido"3. Posteriormente, em 2005, o nome do partido foi alterado para Partido Republicano Brasileiro (PRB) e também foi feito novo manifesto e programa, sob desejo de José Alencar, que na época era vice-presidente da República e filiado ao partido. José Alencar foi visionário ao acreditar que o partido cresceria. Em 2019, o partido passou por uma outra renovaçáo, com alteraçáo do nome para Republicanos, nova ideologia, programa e manifesto. Foram três momentos de mudanças estruturais no partido.

O discurso de "renovação", "nova política", é algo recorrente nas falas dos republicanos, bem como a defesa da República e do bem público, um dos pilares do partido que já constava no primeiro manifesto (do PMR) e na fala inicial de José Alencar. A defesa da República gera a necessidade de uma educação cívica, reeducar eleitores para esse novo modo de fazer política.

Com 14 anos de criaçáo, o partido passou por mudanças e construiu seu novo programa de partido. O objetivo deste trabalho é entender o eixo ideológico do Republicanos e descrever sua identidade. Para tal, será feita a análise de conteúdo para situar o partido em ideologia, identidade e também mapear o discurso econômico e religioso. Foram analisados os dois Manifestos e Programas do PRB 2005-2018 e o atual do Republicanos 2019.

\section{Republicanos: Ideologia e identidade}

O Republicanos é um partido com características de massas que, no seu processo de institucionalização, possuía comportamentos que o colocavam como catch-all. Era necessário ter público - eleitores - para alcançar o poder, mas a proximidade com a IURD apontava a direção para um público religioso.

O partido aqui estudado é uma máquina política. O Republicanos é centralizador e possui como figura-chave um líder, esse líder é alguém admirado pelo coletivo e dele saem todas as demandas do partido. A presença de um líder é extremamente necessária para o conceito de máquina política. Desta maneira, assiste-se a uma diferença: a admiração que se tem não é a personificada na pessoa que se encontra no cargo (DINIZ, 1982, p. 121), e sim no cargo ocupado. Nas palavras de Weber (2003), seria uma admiração racional legal; independentemente da pessoa que ocupa o cargo, obedece às regras que reafirmam aquele cargo.

\footnotetext{
3 Trecho extraído da fala de Vitor Paulo A. dos Santos - Presidente do PMR, no documento que contém manifesto, programa e estatuto do PMR.
} 
Outra característica de uma máquina política, é a homogeneização. A organização interna é homogênea para impedir que atores contrários ocasionem uma dissidência. Dessa maneira, o partido estabelece um esquema de franquia com os níveis estaduais, regionais e municipais. As açóes dos diretórios estáo sempre em acordo com a agenda nacional do partido. Os eventos, como os relacionados ao Dia da Mulher, por exemplo, acontecem em março e todos os diretórios participam, enviam inclusive relatórios (imagens, vídeos) do que ocorreu. Para além dessas, outras demandas de candidaturas ou recuos ocorrem com o aval da gestáo central.

A descrição de máquina política estudada por Diniz (1982) exemplifica muito bem as ações do Republicanos:

A máquina encararia o eleitor não como uma abstração, porém com um ser real com problemas e aspiraçóes reais concretos. Desta forma, seu poder mobilizacional não decorreria de suas preocupaçôes com os grandes temas políticos, abstratos, gerais e distantes, porém de apelos mais específicos, baseados numa teia de relaçôes diretas, quase feudais, entre os representantes locais da máquina e os eleitores de um quarteirão. (DINIZ, 1982, p. 26)

Evidentemente, os serviços prestados pela máquina dirigem-se a grupos bastante diversificados, incluindo filiados, adeptos e eleitores do partido. Para o círculo dos negócios, o chefe político proporciona privilégios e oportunidades especiais que permitem ganhos econômicos imediatos. Para inúmeros outros subgrupos, essa prestação de serviços assume a forma e assistência e ajuda pessoal, envolvendo uma série de situações, desde aconselhamento jurídico, até a distribuição de bolsas de estudo ou a obtenção de uma vaga num hospital para internação de um doente, ou ainda a liberação de um empréstimo de emergência numa agência estatal. Considerando-se o círculo de eleitores, os incentivos utilizados abrangem uma ampla variedade de benefícios, extremamente diferenciados e específicos, que podem ser canalizados para atores individuais e seu círculo familiar, para grupos de vizinhança ou comunais, ou ainda para uma série de categorias sociais particulares de natureza funcional, étnica e religiosa. (DINIZ, 1982, p. 28-29)

Esses trechos publicados em 1982 muito se assemelham à atuação do Republicanos: as relaçóes próximas com eleitorado e o sistema de distribuição de incentivos como mecanismo de coesão. Quando a máquina está no poder, os benefícios tanto são posiçóes na hierarquia interna como cargos na administração. Tal fato gera uma maior integração, coesão e também reafirma a centralização. Afinal, uma cúpula organiza e distribui incentivos. (DINIZ, 1982, p. 42)

A partir do pressuposto de que o Republicanos é uma máquina política, questiona-se a ideologia e identidade do mesmo. Para Tarouco (2007), os programas dos partidos apresentam suas preferências, e não só as questôes gerais. Assim, com o programa, é possível conhecer também a identidade partidária. "Eles são elementos de articulação e encaminhamento de demandas provenientes da sociedade, mesmo quando não cultivam este tipo de vínculo.” (TAROUCO, 2007, p.09) 
Identidade política constitui as preferências por políticas públicas que distinguem um partido de outros. A posição do partido pode ser obtida de 4 modos: atuaçáa parlamentar, discurso próprio, opinião pública e análise acadêmica. Concorda-se com Tarouco (2007) que, de todos os materiais possíveis, o programa dos partidos é melhor, pois parte do que o partido é, diferentemente dos outros, que se baseiam em comportamentos que variam de acordo com demandas e situações. (P.19-22)

A autora estudou os programas partidários e relacionou com o efeito que se dava aos Projetos de Emenda Constitucional (PECs) dos 7 partidos responsáveis por $80 \%$ das propostas de emenda entre os anos de 1988 a 2005: Progressistas (PP), Partido Democrático Trabalhista (PDT), Partido dos Trabalhadores (PT), Partido Trabalhista Brasileiro (PTB), Partido do Movimento Democrático Brasileiro (PMDB), Partido da Frente Liberal (PFL) e Partido da Social Democracia Brasileira (PSDB) .

Tarouco (2007) concluiu que a ênfase programática do partido afeta o texto que será exposto na PEC, já a ideologia não. Esse argumento é interessante pois faz pensar o caso Republicanos: a todo momento a atuação se deu de acordo com o que o programa partidário defendia, com contexto, e náo necessariamente a ideologia importava; tanto que ora se aproximava de um governo de esquerda (PT), centro (MDB) e, atualmente, próximo ao governo de direita (Partido Social Liberal - PSL).

A autora afirmou que os partidos variam pelos domínios que dão em seus programas, que também afetam as PECs apresentadas ao Congresso, bem como a agenda do Congresso. Ou seja, o contexto externo afeta a temática das emendas. A "ideologia de gênero" tornou-se agenda nacional e apareceu em falas de presidenciáveis do ano de 2018. Tal agenda também foi temática em açôes de parlamentares republicanos. Desde 2014, o partido tem publicamente se colocado contrário a políticas públicas voltadas à população LGBT.

O programa criado para o "PRB" foi construído no contexto da chapa Lula-Alencar e ficou em vigor até setembro de $2019^{6}$. Como já dito, José Alencar foi uma figura importante para a construçáo do partido. Nessa conjuntura, pode-se observar que o programa trazia políticas do que poderia enquadrá-lo como “centro-esquerda” que seriam, segundo Tarouco e Madeira (2013):

(i) como categorias indicativas de posicionamento à esquerda: regulação do mercado, planejamento econômico, economia controlada, análise marxista, expansão do Welfare State e referências positivas à classe trabalhadora; (ii) como categorias indicativas de posicionamento à direita: mençóes positivas

\footnotetext{
4 Em 17 de dezembro de 2018 o PMDB alterou o nome para Movimento Democrático Brasileiro (MDB). E em 28 de março de 2007 o PFL altera seu nome para democratas (DEM).

5 Que segundo parlamentares do partido, consiste num debate de cunho pessoal, uma ameaça à família. O debate acaba com a identidade sexual biológica masculina e feminina. E dessa maneira, a discussão de gênero deveria se restringir à família, e não às escolas. E a estas, caberia discutir os gêneros biológicos já definidos como masculino e feminino. Segundo a fala do parlamentar Bulhôes, o debate de outros gêneros poderia desviar as crianças e jovens.

6 Em 23 de setembro de 2019, por meio de um vídeo divulgado no site do partido e nas redes sociais, o presidente nacional Marcos Pereira divulgou o novo programa e manifesto do Republicanos.
} 
às forças armadas, livre iniciativa, incentivos, ortodoxia econômica, limitação do Welfare State e referências favoráveis à classe média e grupos profissionais (para contrastar com as referências à classe operária).(TAROUCO; MADEIRA, 2013, p. 159)

O texto é composto pela defesa dos ideais republicanos clássicos. Inicia-se com referência à liberdade, igualdade e fraternidade; símbolos da Revolução Francesa (1789). Buscavam em seu programa a liberdade individual e uma aproximação dos cidadãos com a política. Apresentam o Estado como soberano e necessário em assegurar o desenvolvimento econômico dos cidadáos individualmente.

Os cinco princípios básicos do partido defendem o poder da democracia representativa, definida pelo voto como poder político legítimo, contrários a qualquer tipo de discriminação. Favoráveis à descentralização; equilíbrio fiscal nos entes federados; desenvolvimento econômico sem degradação ambiental e atenção aos segmentos marginalizados da sociedade.

Na política, deveriam prevalecer os ideais republicanos na condução do Estado, com a esfera pública próxima dos cidadãos, para que estes participassem da vida estatal e cobrassem as açóes do Estado; e o Estado, garantir os direitos sociais a todos cidadáos, cumprir com o que está descrito na Constituição.

O trabalho remunerado é visto como digno (único meio) para os cidadãos sobreviverem, e é dever do Estado criar condiçôes para que os trabalhadores consigam trabalhar; permitir também a propriedade privada como um direito a todos os cidadãos. Ainda na defesa da propriedade privada, a moradia digna deveria ser acessada a todos, com linhas de crédito adequadas às pessoas de baixa renda. Na economia, o capitalismo defendido deve ser regulado pelo Estado, a fim de combinar o governo com a iniciativa privada; potencializar o trabalho humano com responsabilidade ambiental e redistribuição da riqueza, de postos de trabalho e tributação justa.

A educação e a saúde eram as prioridades do governo, o programa estabelecia que a educação básica deveria ser gratuita na esfera governamental ou em estrutura privada. A qualidade deveria estar presente em todos os níveis e todos os profissionais com remuneração adequada. A educação era vista como um meio de ascensão social. A saúde é defendida como direito público universal destinado tanto a brasileiros quanto a estrangeiros.

O partido defendia a paz como mecanismo de solução dos problemas internacionais; as Forças Armadas na defesa nacional com equipamento e remuneração adequados; incentivo à pesquisa tecnológica para a indústria civil. Por fim, o programa encerra assegurando que a religião é de livre escolha do indivíduo, não podendo esse sofrer discriminaçôes.

O programa foi criado por base e defesa dos direitos sociais estabelecidos pela Constituição Federal, aliado ao contexto de ampliação dos gastos sociais no Brasil da época. Deve-se atentar que, na construção do partido, já havia proximidade com o governo federal de esquerda PT, por meio do vice-presidente José de Alencar e por cargos ministeriais: 
Quadro 1 - Ministros do PRB.

\begin{tabular}{|r|l|l|l|l|}
\hline Ano & Presidente & \multicolumn{1}{|c|}{ Partido } & \multicolumn{1}{c|}{ Ministério } & \multicolumn{1}{c|}{ Ministro } \\
\hline 2007 & Lula & PT & Assuntos Estratégicos & Mangabeira Unger \\
\hline 2012 & Dilma & PT & Pesca e Aquicultura & Marcelo Crivella \\
\hline 2014 & Dilma & PT & Pesca e Aquicultura & Eduardo Lopes \\
\hline 2014 & Dilma & PT & Esporte & George Hilton \\
\hline 2016 & Temer & MDB & Comércio & Marcos Jorge \\
\hline 2016 & Temer & MDB & Comércio Exterior e Serviços & Marcos Pereira \\
\hline 2021 & Bolsonaro & Sem Partido & Cidadania & João Roma \\
\hline
\end{tabular}

Fonte: Construída pelos autores a partir dos dados e informações disponíveis no site do Republicanos.

Como demonstrado na imagem acima, o partido foi simpatizante da esquerda desde sua criação até o processo de impeachment, quando então apoiaram o processo contra a presidente Dilma Rousseff. $\mathrm{O}$ apoio ao impeachment, e consequentemente apoio ao governo Temer, resultou em mais um cargo ministerial, e já sinalizava possíveis mudanças na identidade e ideologia, concretizadas com o apoio do presidente Jair Bolsonaro, com quem também teve uma coalizão ministerial.

Nos anos de 2017 e 2018, líderes reuniram-se para construir uma nova imagem, postura e identidade do partido. Diferentemente do que Tarouco (2007) percebeu com os partidos estudados, o partido não se encontrava em queda quando decidiu alterar seu programa. Ao contrário, nas eleições de 2018, o partido cresceu 48,2\%. Anteriormente representava 12 estados brasileiros, passou a representar 19, ocupou o $8^{\circ}$ lugar entre os partidos com mais parlamentares no Congresso, num total de 30 eleitos; foi ainda destaque por ter sido o segundo partido com maior crescimento no Congresso, atrás somente do PSL. O crescimento do Republicanos é visto desde a sua criação:

Tabela 1 - Aumento no número de deputados e senadores eleitos entre 2006-2018 no Republicanos.

\begin{tabular}{|c|c|c|c|c|}
\hline \multicolumn{5}{|c|}{ Eleições Estaduais do Republicanos 2006-2018 } \\
\hline Ano & $\begin{array}{c}\text { Deputados } \\
\text { Estaduais/Distritais }\end{array}$ & $\begin{array}{l}\text { Deputados } \\
\text { Federais }\end{array}$ & Senador & Total \\
\hline 2006 & 3 & 1 & 0 & 4 \\
\hline 2010 & 18 & 8 & 1 & 27 \\
\hline 2014 & 33 & 21 & 0 & 54 \\
\hline 2018 & 42 & 30 & 1 & 73 \\
\hline
\end{tabular}

Fonte: Construída pelos autores a partir do banco de dados do Supremo Tribunal Eleitoral (TSE). 
Tabela 2 - Aumento no número de vereadores e prefeitos eleitos entre 2008-2020 no Republicanos.

\begin{tabular}{|c|c|c|c|}
\hline \multicolumn{4}{|c|}{ Eleições Muncipais do Republicanos 2008-2020 } \\
\hline Ano & Vereadores & Prefeitos & Total \\
\hline 2008 & 780 & 54 & 834 \\
\hline 2012 & 1120 & 81 & 1201 \\
\hline 2016 & 1621 & 103 & 1724 \\
\hline 2020 & 2569 & 211 & 2780 \\
\hline
\end{tabular}

Fonte: Construída pelos autores a partir do banco de dados do Supremo Tribunal Eleitoral (TSE).

As tabelas demonstram um aumento no número de eleitos tanto em cargos a nível municipal quanto estadual. Apenas no senado o partido ainda não obteve avanço, manteve apenas uma cadeira no Congresso, por pleito. Em nenhuma eleição disputada até o momento, o partido teve queda em número de cadeiras, inclusive na última eleição (2020) disputada sem coligaçôes nas campanhas proporcionais, o Republicanos aumentou o número de vereadores, sendo destaque de vitórias em capitais do país.

Desta maneira, entende-se que a mudança aproveita o contexto de crescimento da ideologia de direita, bem como do conservadorismo, ideais atualmente defendidas pelo partido. Nos últimos anos, o partido iniciou uma série de debates que se diferenciavam da postura encontrada no programa. Tal debate já demonstrava uma maior simpatia ao segmento de direita; ideologia que já vinha sendo afirmada pelo próprio partido, declararam que o antigo modelo estava com "seus dias contados", pois o novo governo deveria atuar com comprometimento com a ética e a moral. Publicamente, o partido declarou simpatia ao presidente Jair Bolsonaro, colocou-se à disposição para a construção conjunta. O partido declarou-se favorável a $80 \%$ das pautas do governo federal, governo esse ideologicamente de direita.

A mudança deu-se com auxílio da população simpatizante do partido. Em março de 2019, o partido abriu, em sua plataforma, um espaço para ouvir seus eleitores e militantes. Críticas, elogios, ideias e sugestôes foram enviadas à plataforma digital, a fim de construírem juntos um novo partido; em duas semanas o partido obteve mais de 400 participaçóes. A Convenção Nacional ocorreu em 7 de maio de 2019, apresentou o caminho a ser trilhado pelo novo programa, manifesto, estatuto e a inauguração da nova sede. O logotipo e o nome do partido também se alteraram, de Partido Republicano Brasileiro, para somente "Republicanos", com um logo que retoma traços da primeira imagem do partido, ainda PMR, traz a imagem feminina e tem feito diversos debates sobre inclusão de mulheres na política.

Figura 01 - Logomarcas do partido ao longo do tempo.

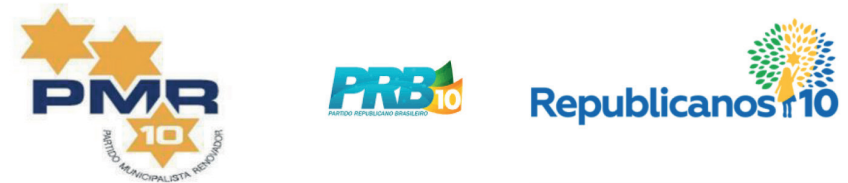

Fonte: Extraído do site do Republicanos (https://republicanos10.org.br/). 
Liberal na economia e conservador nos costumes: Seja bem-vindo ao Republicanos!

O novo programa inicia-se com a fala da Margaret Thatcher: "Não sou uma política de consensos, e sim de convicçóes". O manifesto já se inicia bem posicionado; situado à direita do eixo, simpático a um dos grandes nomes do neoliberalismo inglês; a dama de ferro, a primeira mulher a ocupar o cargo de Primeira-ministra no parlamento britânico.

Para demonstrar a atual posição, o presidente do partido, Marcos Pereira, fez um comparativo com outros partidos à esquerda, centro e direita:

\section{Figura 02 - Eixo Ideológico pelos Republicanos}

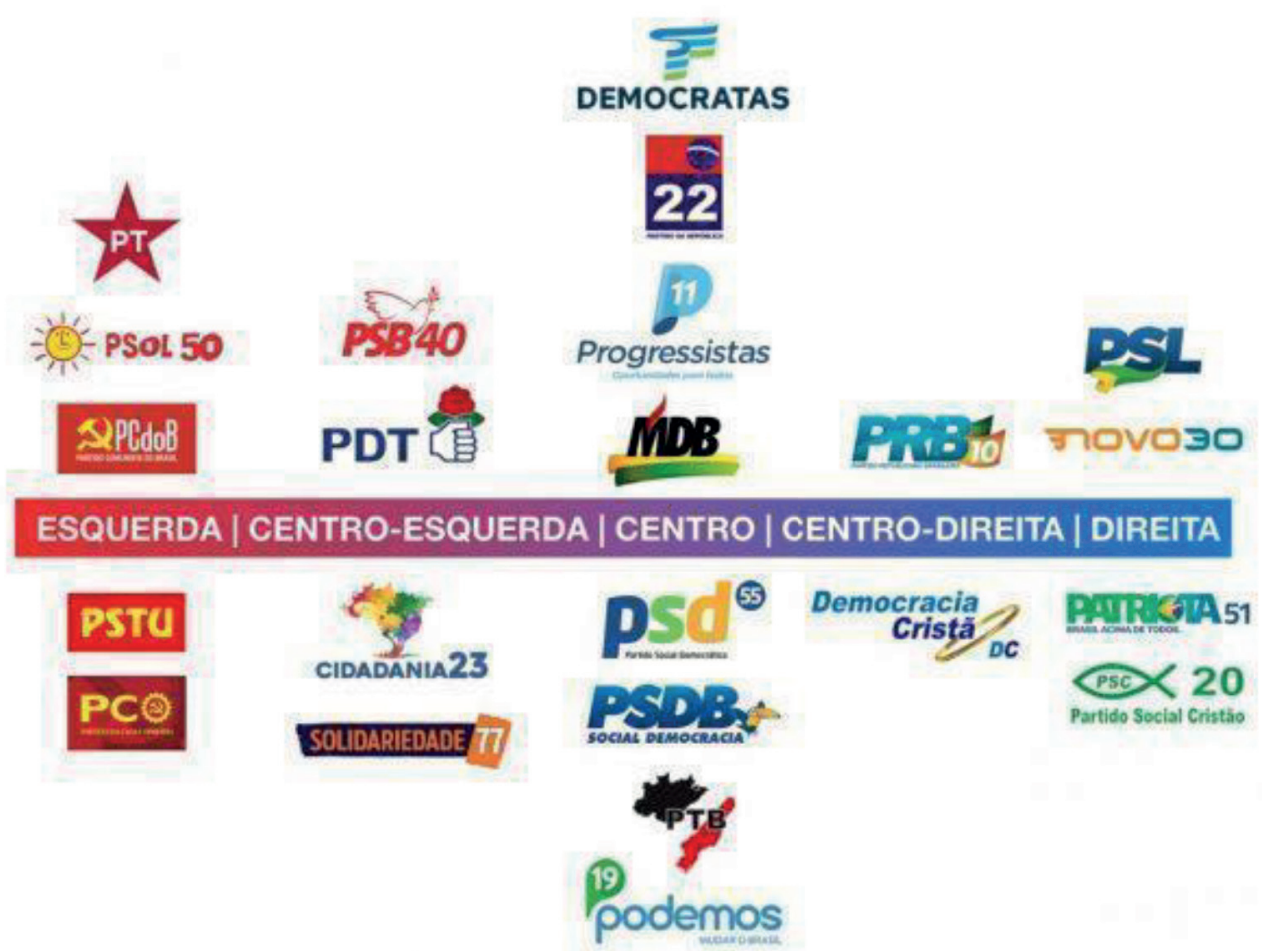

Fonte: Extraído do site do Republicanos (https://republicanos10.org.br/).

O lema deste novo momento partidário é ser "liberal na economia e conservador nos costumes". Assim se abre o primeiro parágrafo do programa, com defesa dos valores cristãos, pautados na família como alicerce fundamental; a defesa da soberania, da livre iniciativa, liberdade econômica e o progresso tecnológico - como inevitável.

Com uma visão durkheimiana de preservação da ordem, a moral aparece como liga social, aquilo que, segundo eles, manteve a sociedade coesa; aliado à forma da tradição e "bons costumes". Para o partido, é o senso de justiça que perpassa de pai para filho, que garantirá o futuro, senso pessoal de justiça. É a família, o modelo de ordem para o funcionamento estatal, 
é dela a referência para o equilíbrio e para que não se caia em tirania, oligarquia ou anarquia individualizada.

O "Criador" aparece como o ser que oportunizou uma sociedade "extraordinária”, capaz de se tornar uma grande potência ao superar seus desafios econômicos, ausentes de inimigos externos e conflitos internos, dotados de riquezas em fauna e flora.

A Constituição é colocada em questáo: é necessário revisá-la; limitar os governos e prevalecer a separação dos poderes de um Estado de Direito. A defesa da propriedade privada é vista como a garantia da estabilidade, responsabilidade e incentivo ao crescimento. Garantir ao trabalhador o fruto do seu trabalho, para que este saia da pobreza. A livre iniciativa, ao lado da ampliação e autonomia do comércio, são defesas do ponto de vista econômico bem como a competitividade industrial. No campo individual, defesa do empreendedorismo e formas de trabalho que partem dos talentos e dons individuais.

Ao fim, parece deixar em aberto a possibilidade de se armar, pois o programa afirma que o cidadão deve ter o direito à defesa da família, patrimônio e de si mesmo.

O partido declara desejo de uma construção coletiva que independe da pessoa ou partido no poder e que cada cidadão deve desejar ser útil na construção, no seio da família, tendo como alicerce a moral cristã e a economia fundamentada na transformação econômica.

O programa apresenta 10 medidas que fundamentam o partido:

1. Estado Soberano - Com defesa do federalismo e municipalismo. É nos municípios a maior força do partido é onde tem mais eleitos. A defesa do município está presente desde o PMR, que afirmava que a defesa do município se dava por entender que o crescimento social inicia-se no município.

2. Governo digital - para o partido, a informatização é capaz de trazer rapidez e eficiência nos serviços públicos. Uma breve pesquisa no site do partido, vê-se que são adeptos à interatividade. Em estudo recente, Braga, Rocha e Carlomagno (2015) afirmaram que o Republicanos é o terceiro partido com "melhor desempenho e com estratégias de comunicação mais diversificadas" (BRAGA; ROCHA; CARLOMAGNO, 2015, p.56). Parlamentares possuem projetos de lei para adesão da internet pública em cidades brasileiras.

3. Ambiente de negócios inovador - Defesa do empreendedorismo como caminho para um desenvolvimento econômico, aliado às transformaçóes tecnológicas. Para tal, defendem também a meritocracia nas relaçôes de trabalho.

4. Indústria forte e competitiva - Um Brasil exportador, com incentivo às pequenas empresas empreendedoras, as quais, segundo eles, empregam-se mais. O campo deve estar alinhado com os avanços tecnológicos, aumentando a qualidade do produto a ser exportado. 
5. Diplomacia e comércio internacional pragmático - importa ao partido que o Brasil esteja presente em grandes eventos e nas cadeias globais de valor. Ser protagonista nas grandes questôes da humanidade.

6. Família e tradição - neste item o partido demonstra-se simpático às pautas popularmente conhecidas como conservadoras. Defesa da vida desde a concepção, da família e do casamento. A valorização da história brasileira, é colocada como importante.

7. Cidadania e justiça social - o programa defende o pacote social como soluçáo para a pobreza. Entretanto, o Welfare State é apresentado de modo residual. Isso significa dizer que o Estado atende somente aos pobres, e aos demais cabe buscar auxílio da família e/ou mercado. Ao mesmo tempo, como mecanismo para não atrapalhar a iniciativa privada, reduzem as regulamentaçôes e impostos. É também conhecido como um modelo liberal. O objetivo é que o governo incentive menos os pacotes sociais, que o indivíduo consiga se manter por sua própria iniciativa. Assim, deve-se incentivar medidas empreendedoras e primeiro emprego e fiscalizar programas sociais.

8. Tecnologias em saúde e educação - Incentivo a mecanismos informatizados no atendimento à saúde, com prontuário e receituário eletrônico, aprimoramento da transparência; mecanismo que auxiliem na fiscalização e redução do desperdício de dinheiro público. Mas na defesa do liberalismo, propóe o incentivo à poupança individual para a saúde. Para educação, defendem que seja mais pragmática e não ideológica; que seja técnica e profissionalizante. No currículo, inserção de conteúdos sobre finanças, tecnologias da informação e empreendedorismo, com um mecanismo pedagógico mais informatizado. Adoção do sistema meritocrático e mensalidade em universidades públicas de acordo com a renda. Algumas dessas medidas já estáo implantadas na educaçáo pública do estado do Rio de Janeiro, como a tecnização do ensino com, inclusive, o curso técnico de empreendedorismo.

9. Defesa nacional e segurança pública - Defesa do cidadáo sem concessões com facçóes criminosas. Revisão do Código Penal, com penas mais duras a crimes hediondos, um sistema prisional privado, combate ao tráfico, luta contra o feminicídio, controle das fronteiras e uso de inteligência por meio de tecnologias. Família com a possibilidade de se defender e defender seus bens.

10. Liberdade de expressão - No ponto de vista da liberdade de expressão, concordam com a necessidade de se haver numa democracia. Defendem as pautas da liberdade de imprensa como a liberdade de expressão, de crença e manifestação da fé religiosa. 


\section{Análise de conteúdo dos programas partidários e manifestos}

Como já dito por Vieira (2011), a autodeclaração do partido pode estar dissociada do que é exposto no seu programa. Por isso, mesmo que o partido atualmente se declare centrodireita, é necessário verificar se o seu manifesto e programa e, consequentemente, suas preferências correspondem à sua autodeclaração. A análise de conteúdo foi utilizada para situar o partido em ideologia. Foram analisados os dois Manifestos e Programas do Republicanos: 2005-2018 (quando era PRB) e o atual 2019 que vigoraram enquanto o partido disputava eleiçóes, direcionando as açóes partidárias. $\mathrm{O}$ manifesto do $\mathrm{PMR}$ só esteve em vigor durante o processo de criação do partido, pois ao ser criado, o partido torna-se PRB com novo manifesto e programa.

Seguindo o método de codificação e análise de Bardin (1977), os manifestos foram codificados a partir do livro de códigos e instruções do The Manifesto Data Collection: South America Versão 2019b. O Manifesto Project analisa programas, manifestos e documentos de partidos que disputam a presidência para construir uma linha ideológica. O livro de códigos de 2019b é uma versão para 5 países da América do Sul, a saber: Argentina, Bolívia, Chile, Uruguai e Brasil, composto por 7 domínios:

\section{Quadro 2 - Domínios do Manifesto Project 2019b}

\begin{tabular}{|l|l|}
\hline \multicolumn{2}{|l|}{ Domínio 1: Relações Internacionais } \\
\hline 101 & Relaç̃̃es Internacionais: Positivas \\
\hline $\mathbf{1 0 2}$ & Relações Internacionais: Negativas \\
\hline $\mathbf{1 0 3}$ & Anti-imperialismo: Anti-imperialismo centrado no \\
\hline $\mathbf{1 0 3}$ & Anti-imperialismo: Influência Financeira Estrangeira \\
\hline 104 & Militarismo Positivo \\
\hline 105 & Militarismo Negativo \\
\hline 106 & Paz \\
\hline 107 & Internacionalismo Positivo \\
\hline 108 & Comunidade / União Europeia Positivo \\
\hline 109 & Internacionalismo Negativo \\
\hline 110 & Comunidade / União Europeia Negativo \\
\hline
\end{tabular}

\begin{tabular}{|l|l|}
\hline \multicolumn{2}{|l|}{ Domínio 2: Liberdade e Democracia } \\
\hline $\mathbf{2 0 1}$ & Liberdade \\
\hline $\mathbf{2 0 1}$ & Direitos Humanos \\
\hline $\mathbf{2 0 2}$ & Democracia Geral Positiva \\
\hline $\mathbf{2 0 2}$ & Democracia Geral Negativa \\
\hline $\mathbf{2 0 2}$ & Democracia Representativa Positiva \\
\hline $\mathbf{2 0 2}$ & Democracia Direta Positiva \\
\hline $\mathbf{2 0 3}$ & Constitucionalismo Positivo \\
\hline $\mathbf{2 0 4}$ & Constitucionalismo Negativo \\
\hline
\end{tabular}




\begin{tabular}{|l|l|}
\hline \multicolumn{2}{|l|}{ Domínio 3: Sistema Político } \\
\hline $\mathbf{3 0 1}$ & Descentralização \\
\hline $\mathbf{3 0 2}$ & Centralização \\
\hline $\mathbf{3 0 3}$ & Eficiência Governamental e Administrativa \\
\hline $\mathbf{3 0 4}$ & Corrupção Política \\
\hline $\mathbf{3 0 5}$ & Autoridade Política: Competência Partidária \\
\hline $\mathbf{3 0 5}$ & Autoridade Política: Competência Pessoal \\
\hline $\mathbf{3 0 5}$ & Autoridade Política: Governo Forte \\
\hline $\mathbf{3 0 5}$ & Transição: Elites Pré-democrática Positivas \\
\hline $\mathbf{3 0 5}$ & Transição: Elites Pré-democráticas Negativas \\
\hline $\mathbf{3 0 5}$ & Transição: Reabilitação e Compensação \\
\hline
\end{tabular}

\begin{tabular}{|l|l|}
\hline \multicolumn{2}{|l|}{ Domínio 4: Economia } \\
\hline $\mathbf{4 0 1}$ & Economia de Mercado Livre \\
\hline $\mathbf{4 0 2}$ & Incentivos: Positivos \\
\hline $\mathbf{4 0 3}$ & Regulação do Mercado \\
\hline $\mathbf{4 0 4}$ & Planejamento Econômico \\
\hline $\mathbf{4 0 5}$ & Corporativismo e Economia Mista \\
\hline $\mathbf{4 0 6}$ & Protecionismo Positivo \\
\hline $\mathbf{4 0 7}$ & Protecionismo Negativo \\
\hline $\mathbf{4 0 8}$ & Metas Econômicas \\
\hline $\mathbf{4 0 9}$ & Gestão da Demanda Keynesiana \\
\hline $\mathbf{4 1 0}$ & Crescimento Econômico Positivo \\
\hline $\mathbf{4 1 1}$ & Tecnologia e Infraestrutura: Positiva \\
\hline $\mathbf{4 1 2}$ & Controle Econômico \\
\hline $\mathbf{4 1 3}$ & Nacionalizaç̃o \\
\hline $\mathbf{4 1 4}$ & Economia Ortodoxa \\
\hline $\mathbf{4 1 5}$ & Análise Marxista \\
\hline $\mathbf{4 1 6}$ & Economia Anticrescimento: Positiva \\
\hline $\mathbf{4 1 6}$ & Sustentabilidade: Positiva \\
\hline
\end{tabular}

\begin{tabular}{|l|l|}
\hline \multicolumn{2}{|l|}{ Domínio 5 : Estado de Bem-Estar Social e Igualdade } \\
\hline $\mathbf{5 0 1}$ & Proteção Ambiental \\
\hline $\mathbf{5 0 2}$ & Cultura Positiva \\
\hline $\mathbf{5 0 3}$ & Igualdade Positiva \\
\hline $\mathbf{5 0 4}$ & Expansão do Estado de Bem-Estar Social \\
\hline $\mathbf{5 0 5}$ & Limitação do Estado de Bem-Estar social \\
\hline $\mathbf{5 0 6}$ & Expansão da Educação \\
\hline $\mathbf{5 0 7}$ & Limitação da Educação \\
\hline
\end{tabular}




\begin{tabular}{|l|l|}
\hline \multicolumn{2}{|l|}{ Domínio 6: Tecido Social } \\
\hline 601 & Modo de Vida Geral Nacional: Positivo \\
\hline 601 & Modo de Vida Nacional: Imigração: Negativo \\
\hline 602 & Modo de Vida Geral Nacional: Negativo \\
\hline 602 & Modo de Vida Nacional: Imigração: Positivo \\
\hline 603 & Moralidade Tradicional: Positiva \\
\hline 604 & Moralidade Tradicional: Negativa \\
\hline 605 & Lei e Ordem Positiva \\
\hline 605 & Lei e Ordem: Negativo \\
\hline 606 & Pensamento Cívico Geral Positivo \\
\hline 606 & Pensamento Cívico: Ativismo Bottom-Up \\
\hline 607 & Multiculturalismo Geral Positivo \\
\hline 607 & Multiculturalismo: Diversidade de Imigrantes \\
\hline 607 & Multiculturalismo: Direitos Indígenas: Positivos \\
\hline 608 & Multiculturalismo Geral Negativo \\
\hline 608 & Multiculturalismo: Assimilação de Imigrantes \\
\hline 608 & Multiculturalismo: Direitos Indígenas: Negativo \\
\hline
\end{tabular}

\begin{tabular}{|l|l|}
\hline \multicolumn{2}{|l|}{ Domínio 7: Grupos Sociais } \\
\hline $\mathbf{7 0 1}$ & Grupos Trabalhistas Positivos \\
\hline $\mathbf{7 0 2}$ & Grupos Trabalhistas Negativos \\
\hline $\mathbf{7 0 3}$ & Agricultura e Agricultores: Positivo \\
\hline $\mathbf{7 0 3}$ & Agricultura e Agricultores: Negativo \\
\hline $\mathbf{7 0 4}$ & Classe Média e Grupos Profissionais \\
\hline $\mathbf{7 0 5}$ & Grupos Minoritários Desprivilegiados \\
\hline $\mathbf{7 0 6}$ & Grupos Demográficos Não-econômicos \\
\hline
\end{tabular}

Fonte: Extraído do Manifesto Project 2019b.

A partir da leitura dos Manifestos e programas do Republicanos, foi possível codificar em códigos de 6 domínios. O domínio 7 não pode ser colocado em documento com orientação ideológica, como é o Manifesto e Programa de 2019, e também não obteve ocorrências no Manifesto e Programa de 2005-2018: 
Quadro 3 - Domínios Codificados nos Manifestos e Programas do Partido Republicanos (2005-2018 e 2019)

\begin{tabular}{|l|l|}
\hline 104 & Militarismo Positivo \\
\hline 105 & Militarismo Negativo \\
\hline 106 & Paz \\
\hline 107 & Internacionalismo Positivo \\
\hline 109 & Internacionalismo Negativo \\
\hline 2011 & Liberdade \\
\hline 2012 & Direitos Humanos \\
\hline 2021 & Democracia Geral positiva \\
\hline 203 & Constitucionalismo Positivo \\
\hline 204 & Constitucionalismo Negativo \\
\hline 301 & Descentralizacão \\
\hline 302 & Centralizacão \\
\hline 401 & Livre Iniciativa \\
\hline 410 & Crescimento Econômico Positivo \\
\hline 411 & Tecnologia e Infraestrutura: Positiva \\
\hline 413 & Nacionalizacão \\
\hline 4162 & Sustentabilidade: Positiva \\
\hline 503 & Igualdade Positiva \\
\hline 504 & Expansão do Estado de Bem-Estar Social \\
\hline 505 & Limitacão do Estado de Bem-Estar Social \\
\hline 506 & Expansão da Educacão \\
\hline 507 & Limitacão da Educacão \\
\hline 601 & Nacionalismo Geral: Positivo \\
\hline 603 & Moralidade Tradicional: Positiva \\
\hline 6051 & Lei e Ordem Positiva \\
\hline 6081 & Multiculturalismo Geral Negativo \\
\hline & \\
\hline
\end{tabular}

Fonte: Construído pelos autores a partir dos dados do banco do Manifesto Project 2019b.

O Manifesto Project considera ideologia de direita nos seguintes códigos: 104, 201_1, 201_2, 203, 305_1, 305_2, 305_3, 305_4, 305_5, 305_6, 401, 402, 407, 414, 505, 601_1, 601_2, 603, 605_1, 605_2, 606_1 e 606_2. Já à esquerda: 103_1, 103_2, 105, 106, 107, 202_1, 202_3, 202_4, 403, 404, 406, 412, 413, 504, 506 e 701. Entretanto, conforme a imagem acima, os Manifestos e Programas também foram codificados nos códigos: 109, 204, 301, 302, 410, 411, 416_2, 503, 504, 507 e 608_1. Deste modo, com leitura das posiçóes tomadas pelo partido, o histórico brasileiro e autores (TAROUCO; MADEIRA,2013; TAROUCO, 2013), a linha ideológica direita-esquerda foi adaptada da seguinte forma: 
Quadro 4 - Adaptaçáo ao modelo do Manifesto Project 2019a para o caso do Republicanos

\begin{tabular}{|l|l|}
\hline \multicolumn{2}{|c|}{ Esquerda } \\
\hline 105 & Militarismo Negativo \\
\hline 106 & Paz \\
\hline 107 & Internacionalismo Positivo \\
\hline 202 & Democracia Geral positiva \\
\hline 204 & Constitucionalismo Negativo \\
\hline 301 & Descentralizacão \\
\hline 413 & Nacionalizacão \\
\hline 416 & Sustentabilidade: Positiva \\
\hline 503 & Igualdade Positiva \\
\hline 504 & Expansão do Estado de Bem-Estar Social \\
\hline 506 & Expansão da Educacão \\
\hline
\end{tabular}

\begin{tabular}{|l|l|}
\hline \multicolumn{2}{|c|}{ Direita } \\
\hline 104 & Militarismo Positivo \\
\hline 109 & Internacionalismo Negativo \\
\hline 201 & Liberdade \\
\hline 201 & Direitos humanos \\
\hline 203 & Constitucionalismo Positivo \\
\hline 302 & Centralizacão \\
\hline 401 & Livre Iniciativa \\
\hline 410 & Crescimento Econômico Positivo \\
\hline 411 & Tecnologia e Infraestrutura: Positiva \\
\hline 505 & Limitacão do Estado de Bem-Estar Social \\
\hline 507 & Limitacão da Educacão \\
\hline 601 & Nacionalismo Geral: Positivo \\
\hline 603 & Moralidade tradicional: Positiva \\
\hline 605 & Lei e Ordem Positiva \\
\hline 608 & Multiculturalismo Geral Negativo \\
\hline
\end{tabular}

Fonte: Construído pelos autores a partir dos dados do banco do Manifesto Project 2019b e Programas e Manifestos do Republicanos.

O código 411 - Tecnologia e infraestrutura positiva foi considerado de direita pois está relacionado ao desenvolvimento econômico pró-mercado.

A frequência de cada código nos textos dos Manifestos e Programas do Republicanos demonstra a ênfase que eles dão e a imagem que desejam passar de si mesmos: 
Tabela 03: Porcentagem da frequência do texto nos códigos em cada Manifesto e Programa do Republicanos

\begin{tabular}{|c|c|c|c|c|c|c|c|c|c|c|c|c|c|c|c|c|}
\hline Manifestos/Programas & \multicolumn{16}{|c|}{ Direita Adaptada } \\
\hline Códigos & 104 & 109 & 201_1 & 201_2 & 203 & 302 & 401 & 410 & 411 & 505 & 507 & 601_1 & 603 & 605 & $608 \_1$ & Total \\
\hline Manifesto/Programa 2005-2018 & 2,74 & 0 & 1,06 & 0,42 & 1,66 & 8,89 & 0,97 & 0 & 0 & 0 & 0 & 0,16 & 0,08 & 0 & 0 & 15,98 \\
\hline Manifesto/Programa 2019 & 0.63 & 2,06 & 0,23 & 1,35 & 0,21 & 0,8 & 3,28 & 0.9 & 0,65 & 1,75 & 0,27 & 0,29 & 5,18 & 1,69 & 0,23 & 19,52 \\
\hline
\end{tabular}

Fonte: Construído pelos autores a partir dos dados do banco do Manifesto Project 2019b e Programas e Manifestos do Republicanos.

Tabela 04: Porcentagem da frequência do texto nos códigos em cada Manifesto e Programa do Republicanos

\begin{tabular}{|c|c|c|c|c|c|c|c|c|c|c|c|c|}
\hline Manifestos/Programas & \multicolumn{12}{|c|}{ Esquerda Adaptada } \\
\hline Códigos & 105 & 106 & 107 & $202 \_1$ & 204 & 301 & 413 & $416 \_2$ & 503 & 504 & 506 & Total \\
\hline Manifesto/Programa 2005-2018 & 0 & 1,33 & 0 & 4,38 & 0 & 2,22 & 1,28 & 0,87 & 2,75 & 2,4 & 0,74 & 15,97 \\
\hline Manifesto/Programa 2019 & 0,19 & 0 & 2,18 & 0,71 & 0,13 & 0,14 & 0 & 0 & 0,14 & 0,16 & 0 & 3,65 \\
\hline
\end{tabular}

Fonte: Construído pelos autores a partir dos dados do banco do Manifesto Project 2019b e Programas e Manifestos do Republicanos.

Já nessas imagens é possível perceber que o Manifesto e Programa de 2005-2018 fica dividido entre as duas ideologias, com 0,01\% mais frequente à direita, o que demonstra seu caráter genérico. Já o Manifesto e Programa de 2019 é visivelmente mais frequente aos códigos de direita. Fazendo o cálculo, é possível perceber a que ideologia cada Manifesto Programa corresponde:

Tabela 05- Cálculo de posicionamento Direita-Esquerda

\begin{tabular}{|lll|l|}
\hline \multicolumn{1}{|c|}{ Manifestos/Programas } & \multicolumn{1}{c|}{ Esquerda } & \multicolumn{1}{c|}{ Direita } & Direita - Esquerda \\
\hline Manifesto /Programa 2005-2018 & 15,97 & 15,98 & 0,01 \\
Manifesto/Programa 2019 & 3,65 & 19,52 & 15,87 \\
\hline
\end{tabular}

Fonte: Construído pelos autores a partir dos dados do banco do Manifesto Project 2019b e Programas e Manifestos do Republicanos.

De acordo com o modelo, o Manifesto Programa de 2005-2018 não tinha uma ideologia definida e o próprio Republicanos concorda com essa afirmação. É bom lembrar que esse manifesto foi proposto para o partido quando ainda se chamava PRB, na sua criação. Criação num contexto da chapa Lula-Alencar e ficou em vigor até setembro de $2019^{7}$. Como já dito, José Alencar foi uma figura importante para a construçáo do partido. Nessa conjuntura, pode-se observar que o programa trazia políticas do que poderia enquadrá-lo como "centro-esquerda". É em 2018 que se intensifica a mobilização para mudança da identidade partidária e, para ter

7 Em 23 de setembro de 2019, por meio de um vídeo divulgado no site do partido e nas redes sociais, o presidente nacional Marcos Pereira divulgou o novo programa e manifesto do Republicanos. 
um discurso de acordo com o programa, foi necessário mudar o Programa e Manifesto para que estabelecessem a visão direitista. Direita, pelos valores morais, pela tradição, pela família, por Deus e pela economia meritocrática e liberal. Centro, porque entendem que em política é necessário fazer colisão e, para fazer colisão, o extremo não ajuda, é preciso diálogo e relaçóes amistosas.

Inclusive no domínio das Relaçôes Internacionais, no código Militarismo Positivo, o partido vê a necessidade da defesa do seu território e também defende a paz como solução dos conflitos. Os militares são bem-vistos e merecedores de estrutura e salário digno, todavia em nenhum momento o partido se coloca como favorável a uma intervenção militar ou guerra.

O domínio 4, do livro de códigos do Manifesto Project 2019b, constitui a Economia. Os Republicanos compartilham de um discurso meritocrático e capitalista, sem abandonar o assistencialismo pontual. No partido, alguns parlamentares ficaram conhecidos por práticas assistencialistas. Crivella, bispo licenciado e ex-prefeito do Rio de Janeiro, ficou mundialmente conhecido pelo seu trabalho assistencialista no continente Africano e, no Brasil, com o projeto "Vamos irrigar o sertáo" na Bahia. Desta forma, o partido defende um mercado liberal, meritocrático, com um estado de bem-estar residual, assistência necessária até que a pessoa consiga voltar para o mercado, quando terá dignidade para viver a vida.

O código Moralidade Tradicional Positiva contempla as tradiçôes, conceito de família monogâmica, heteronormativa e a religião. Nessa mudança pós-impeachment de 2015, o partido intensifica suas falas conservadoras: antipautas LGBTQIA+, defesa da vida a partir da concepção, contrários à legalização do aborto, entre outros. Ao mesmo tempo, também tornamse mais comuns as falas pela defesa de mais liberdade econômica e incentivo ao empresariado como solução para empregabilidade e para o fim da pobreza. Por vezes o discurso colocava-se também contrário às cotas. Este código é o mais frequente no atual Manifesto e Programa, o texto é repleto de uma defesa moral e da afirmação do cristianismo.

O Manifesto e Programa de 2019 é visivelmente direitista. Não ficam dúvidas. É construído no contexto de ascensão da direita e de corte de pacotes sociais. O presidente afirmou que é um retorno ao começo. E é possível ver traços do programa e manifesto do PMR neles - como a defesa da família e o cristianismo. O logotipo e o nome do partido também se alteraram, de Partido Republicano Brasileiro, para somente "Republicanos", com um logo que retoma traços da primeira imagem do partido, ainda PMR.

A mudança não traiu a ideia inicial do partido. Este já era conservador e cristão na sua criaçáo, o manifesto e programa do PMR demonstram isso! Entretanto, num contexto de esquerda em ascensão, construíram um programa genérico que, durante muito tempo, foi simpático à ideologia de esquerda. A retomada à direita ocorreu gradativamente, o partido já se encontrava estabelecido no cenário político, com destaque nos pleitos. Não mudaram devido a uma crise. Com as decisóes, alianças e falas dos líderes, a crítica à proposta dos governos de esquerda e afastamento do governo PT - que culminou no apoio ao impeachment - ficou 
visível o seu deslocamento à direita. Um processo gradativo e feito com reflexão e pesquisa do núcleo gestor.

\section{Consideraçóes Finais}

O programa e manifesto do PMR em 2003 era cristão e com características de esquerda; já o do PRB em 2005 era genérico, não possuía religião e demonstrava uma tendência para a centro-esquerda; por fim, o do Republicanos de 2019 está de acordo com a autoidentificaçáo do partido: centro-direita e cristão. Centro, porque estão longe dos extremos, são favoráveis à paz e ainda possuem algumas políticas de assistência, embora pontuais. Direita, pelo conservadorismo nas pautas dos costumes - como a defesa da família e liberalismo econômico. Os manifestos possuem relação com o contexto em que o partido encontrava-se: proximidade com governos de esquerda - rompimento com governos de esquerda - proximidade com governos de direita. O partido inicia-se como um partido cristão e retoma esse lugar, mantém a necessidade de políticas pontuais de assistência e continua por defender a necessidade da inserção das tecnologias no governo e o republicanismo.

Essa coerência textual do atual manifesto e programa foi fruto de organização coletiva para além do núcleo partidário, em março de 2019, o partido abriu em sua plataforma, um espaço para ouvir seus eleitores e militantes. $\mathrm{O}$ trabalho iniciou com diálogo e estudo do grupo dirigente, os oligarcas do grupo. Posteriormente, críticas, elogios, ideias e sugestôes foram enviadas à plataforma digital a fim de construírem juntos um novo partido; em duas semanas, o partido obteve mais de 400 participações. A Convenção Nacional ocorreu em 7 de maio de 2019, apresentou o caminho a ser trilhado pelo novo programa, manifesto, estatuto e a inauguração da nova sede situada em Brasília-DF.

O Republicanos tem 15 anos e se destaca com crescimento ascendente. Possui o maior número de cadeiras na Frente parlamentar evangélica e é o partido com maior expressão entre os que defendem o cristianismo, a saber, Partido Trabalhista Cristão (PTC), Partido Social Cristão (PSC), Partido Mobilização Nacional (PMN), Democracia Cristã (DC) e Patriota. No Brasil, entre os 33 partidos cadastrados, estes 06 fazem defesa explícita da religiáo e, no caso brasileiro, essa relação está sempre vinculada ao cristianismo. O primeiro programa e manifesto do partido - quando era PMR - já se apresentava como assumidamente cristão e "reconhecimento do Deus supremo", ou seja, o partido nasceu com uma religiáo e retoma essa imagem com o manifesto e programa de 2019.

Em se tratando do Republicanos enquanto um partido de máquina, tem como interesse a proximidade com sua base. A consulta pública do partido demonstrou mais uma vez esse interesse. Ao dar ouvidos aos eleitores, eles se colocaram como aquilo que deveriam ser - seu representante nas questóes políticas. A máquina republicana tem sido eficaz na capacidade de angariar votos e conquistar espaços na arena política. Em 15 anos de existência, o partido tem se destacado e no último pleito foi o partido com a $10^{\text {a }}$ maior bancada municipal, além de 
estar no ranking dos partidos que mais elegeram vereadores em capitais. Também tem mantido uma coalizão com o governo federal, com todos os presidentes tiveram cargos ministeriais.

O Republicanos possui coerência em seu discurso e autoidentificação. Veem-se como centro-direita e seus documentos demonstram isso. Como um partido centralizado que busca homogeneidade discursiva, o partido atua com seminários e debates das temáticas defendidas por eles. Seus militantes e lideranças são estimulados a conhecer e compreender suas visóes, valores, interesses e defesas.

\section{Referências}

BARDIN, L. Análise de conteúdo. Lisboa: Ediçôes 70, 1977.

BENEVIDES, C. do V. Um Estado de bem-estar social no Brasil. Dissertação (Mestrado em Economia) - Departamento de Economia, Universidade Federal Fluminense, Rio de Janeiro, 2011.

BRAGA, S.; ROCHA, L. C.; CARLOMAGNO, M. C. A Internet e os partidos políticos brasileiros. Cadernos Adenauer, v. 16, p. 47-74, 2015.

BUDGE, I. et al. Mapping policy preferences: estimates for parties, electors, and governments, 1945-1998. Oxford University Press on Demand, 2001.

COWAN, Benjamin Arthur. "Nosso Terreno". Crise moral, política evangélica e a formação da 'Nova Direita' brasileira. Varia História, v. 30, n. 52, p. 101-125, 2014.

DINIZ, Eli. Voto e máquina política: patronagem e clientelismo no Rio de Janeiro. Rio de Janeiro: Paz e Terra, 1982.

DUVERGER, Maurice. Los partidos políticos. México: Fondo de Cultura Económica, 2002.

GOSNELL, Harold Foote. Machine politics: Chicago model. 2. ed. Chicago: University of Chicago Press, 1937.

KRAUSE, Werner; LEHMANN, Pola; MARTTHIEß, Theres; MERZ, Nicolas, REGEL, Sven, WEßELS, Bernhard. The manifesto data collection: South America. Version 2019b. Berlin: Wissenschaftszentrum Berlin für Sozialforschung (WZB). 2019. Disponível em <https://doi. org/10.25522/manifesto.mpdssa.2019b>. Acesso em: 18 nov. 2020.

TAROUCO, G. da S.; MADEIRA, R. M. Partidos, programas e o debate sobre esquerda e direita no Brasil. Revista de Sociologia e Política, v. 21, n. 45, p. 149-165, 2013.

TAROUCO, G. da S. Os partidos e a constituição: ênfases programáticas e propostas de emenda. Tese (Doutorado em Ciência Política) - Faculdade de Ciências Sociais, Universidade Federal do Rio de Janeiro, Rio de Janeiro. 2007.

Esquerda e direita no sistema partidário brasileiro: análise de conteúdo de documentos programáticos. Revista Debates (UFRGS), v. 7, p. 93-114, 2013.

VIEIRA, Soraia Marcelino. O Partido da Social Democracia Brasileira: trajetória e ideologia. 
Tese (Doutorado em Ciência Política) - Instituto de Estudos Sociais e Políticos, Universidade Estadual do Rio de Janeiro, 2012.

WEBER, Max. A política como vocaçáo. Brasília: EdUnB, 2003.

WOLF, Paulo José Whitaker; OLIVEIRA, Giuliano Contento de. Os Estados de Bem-Estar Social da Europa Ocidental: tipologias, evidências e vulnerabilidades. Economia e Sociedade, v. 25, n. 3, p. 661-694, 2016.

\section{Site consultado}

www.prb.com

\section{Programa partidário}

https://www.prb10.org.br/programa/

\section{Matérias do site}

PRB. PRB/Republicanos: por que conservador? 2019. Disponível em: https://www.prb10. org.br/noticias/palavra-do-presidente/prb-republicanos-por-que-conservador/. Acesso em: 30 jun. 2019.

Ideais republicanos. 2019. Disponível em:https://www.prb10.org.br/noticias/ palavra-do-presidente/ideais-republicanos/. Acesso em: 30 jun. 2019.

Republicanos: uma nova era. 2019. Disponível em: https://www.prb10.org.br/ noticias/palavra-do-presidente/republicanos-uma-nova-era/.Acesso em: 30 jun. 2019.

Grande passo na consolidação do Republicanos. 2019. Disponível em: https://www. prb10.org.br/noticias/palavra-do-presidente/grande-passo-na-consolidacao-do-republicanos/. Acesso em: 30 jun. 2019.

1 semana para grandes mudanças. 2019. Disponível em: https://www.prb10.org.br/ noticias/palavra-do-presidente/1-semana-para-grandes-mudancas/. Acesso em: 30 jun. 2019.

Consulta aos republicanos já tem resultado parcial. 2019. Disponível em: https:// www.prb10.org.br/noticias/palavra-do-presidente/consulta-aos-republicanos-ja-tem-resultadoparcial/. Acesso em: 30 jun. 2019.

Um novo PRB vem aí e você pode contribuir com ideias. 2019. Disponível em: https://www.prb10.org.br/noticias/palavra-do-presidente/um-novo-prb-vem-ai-e-voce-podecontribuir-com-ideias/. Acesso em: 30 jun. 2019.

Construindo o futuro do partido. 2019. Disponível em: https://www.prb10.org.br/ noticias/palavra-do-presidente/construindo-o-futuro-do-partido/. Acesso em: 30 jun. 2019.

.Republicanos de todo o Brasil. 2019. Disponível em: https://www.prb10.org.br/ noticias/palavra-do-presidente/republicanos-de-todo-o-brasil/. Acesso em: 30 jun. 2019.

-.2019 chega com tudo. 2019. Disponível em:https://www.prb10.org.br/noticias/ palavra-do-presidente/2019-chega-com-tudo/. Acesso em: 30 jun. 2019. 
. A batalha será ganha. 2018. Disponível em:https://www.prb10.org.br/noticias/ palavra-do-presidente/a-batalha-sera-ganha/. Acesso em: 30 jun. 2019.

.O velho modelo está com os dias contados. 2018. Disponível em: https://www. prb10.org.br/noticias/palavra-do-presidente/o-velho-modelo-esta-com-os-dias-contados/. Acesso em: 30 jun. 2019.

A missáo de Bolsonaro. 2018. Disponível em:https://www.prb10.org.br/noticias/ palavra-do-presidente/a-missao-de-bolsonaro/. Acesso em: 30 jun. 2019.

Ninguém faz nada sozinho. 2018. Disponível em: https://www.prb10.org.br/ noticias/palavra-do-presidente/ninguem-faz-nada-sozinho/. Acesso em: 30 jun. 2019.

Queremos um Brasil melhor. 2018. Disponível em: https://www.prb10.org.br/ noticias/palavra-do-presidente/queremos-um-brasil-melhor/. Acesso em: 30 jun. 2019.

A vontade popular no segundo turno. 2018. Disponível em:https://www.prb10. org.br/noticias/palavra-do-presidente/a-vontade-popular-no-segundo-turno/. Acesso em: 30 jun. 2019.

A renovação está em nossas mãos. 2018. Disponível em: https://www.prb10.org.br/ noticias/palavra-do-presidente/a-renovacao-esta-em-nossas-maos/. Acesso em: 30 jun. 2019.

Juntos e com garra na reta final. 2018. Disponível em:https://www.prb10.org.br/ noticias/palavra-do-presidente/juntos-e-com-garra-na-reta-final/. Acesso em: 30 jun. 2019.

.Por que algumas candidaturas estáo se derretendo? 2018. Disponível em: https:// www.prb10.org.br/noticias/palavra-do-presidente/por-que-algumas-candidaturas-estao-sederretendo/. Acesso em: 30 jun. 2019.

Oportunidade de mudança. 2018. Disponível em: https://www.prb10.org.br/ noticias/palavra-do-presidente/oportunidade-de-mudanca/. Acesso em: 30 jun. 2019.

.Repensando o Brasil. 2018. Disponível em: https://www.prb10.org.br/noticias/ palavra-do-presidente/repensando-o-brasil/. Acesso em: 30 jun. 2019.

O velho olhar sobre política. 2018. Disponível em: https://www.prb10.org.br/ noticias/palavra-do-presidente/o-velho-olhar-sobre-politica/. Acesso em: 30 jun. 2019. 